\title{
Medial Circumflex Femoral Artery Perforator Flap in a Seven-Year-Old Boy for a Degloving Ankle Injury: A case report in immediate reconstruction
}

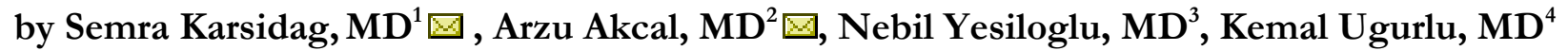

The Foot and Ankle Online Journal 3 (5): 1

Degloving injuries and high-energy trauma of distal lower extremity is fortunately rare in children and there are a limited number of articles that have been written about microsurgical management of these injuries. In the pediatric population, it was realized that free flaps could be safely used in the treatment of soft-tissue defects. First, critical issues as to the feasibility and reliability of the intervention in children were rapidly overcome as it was realized that the relative size of the pedicle vessels is larger in children than that in adults. The same holds true for the perforator vessels; although they can be relatively small in children, their relative size compared with the size of the child's body is greater than that in adults. In this case report, a 7 year-old boy sustained a severe mangling, crushing type injury of his right ankle in an elevator-door related accident. He sustained a degloving injury of the anterolateral aspect of the ankle, an ipsilateral tarsal fracture and ankle subluxation. We have confirmed the versatility and safety of the medial circumflex femoral artery perforator flap in this type of injury within the first 24-hours after the injury. Without undermining, the donor site was closed directly in an almost linear scaring the gluteal fold that can be easily concealed. We found the medial circumflex femoral artery perforator flap is one of safe and suitable flap choice in children who have a defect on the distal one third of tibia in the acute period of trauma.

Key words: Medial circumflex femoral artery perforator flap, children, fasciocutaneous. reproduction in any medium, provided the original work is properly cited. (The Foot and Ankle Online Journal (www.faoj.org)

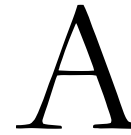
compound muscle-skin flap combining the medial thigh and underlying gracilis muscle was first used by Orticochea to demonstrate that a "delay" could thereby be avoided while allowing immediate transfer of a large skin flap. ${ }^{1}$

The authors have no conflict of interest to disclose for this study.

\footnotetext{
Address correspondence to: Semra Karsidag, MD.

Gazi Berkay cad. No:13/9 Sisli- Istanbul-Turkey

Tel and Fax: +90-212-225- 94-84

E-mail: semrakarsidag@yahoo.com

1,2,3,4 Department of Plastic and Reconstructive Surgery, Sisli Etfal Research and Educational Hospital, Istanbul, Turkey.
}

McCraw, et al., ${ }^{2}$ then defined the concept of perforating arteries of muscle that made this gracilis musculocutaneous flap an integral skin-muscle unit for reliable "primary" use as a local flap to cover the perineum, genitalia, medial thigh, groin, perirectal, and ischial regions. ${ }^{3}$ Hallock demonstrated that the superior medial thigh skin can also be transferred as a free "perforator flap" based on the gracilis musculocutaneous perforators alone, and named this the medial circumflex femoral perforator flap. ${ }^{4}$ 


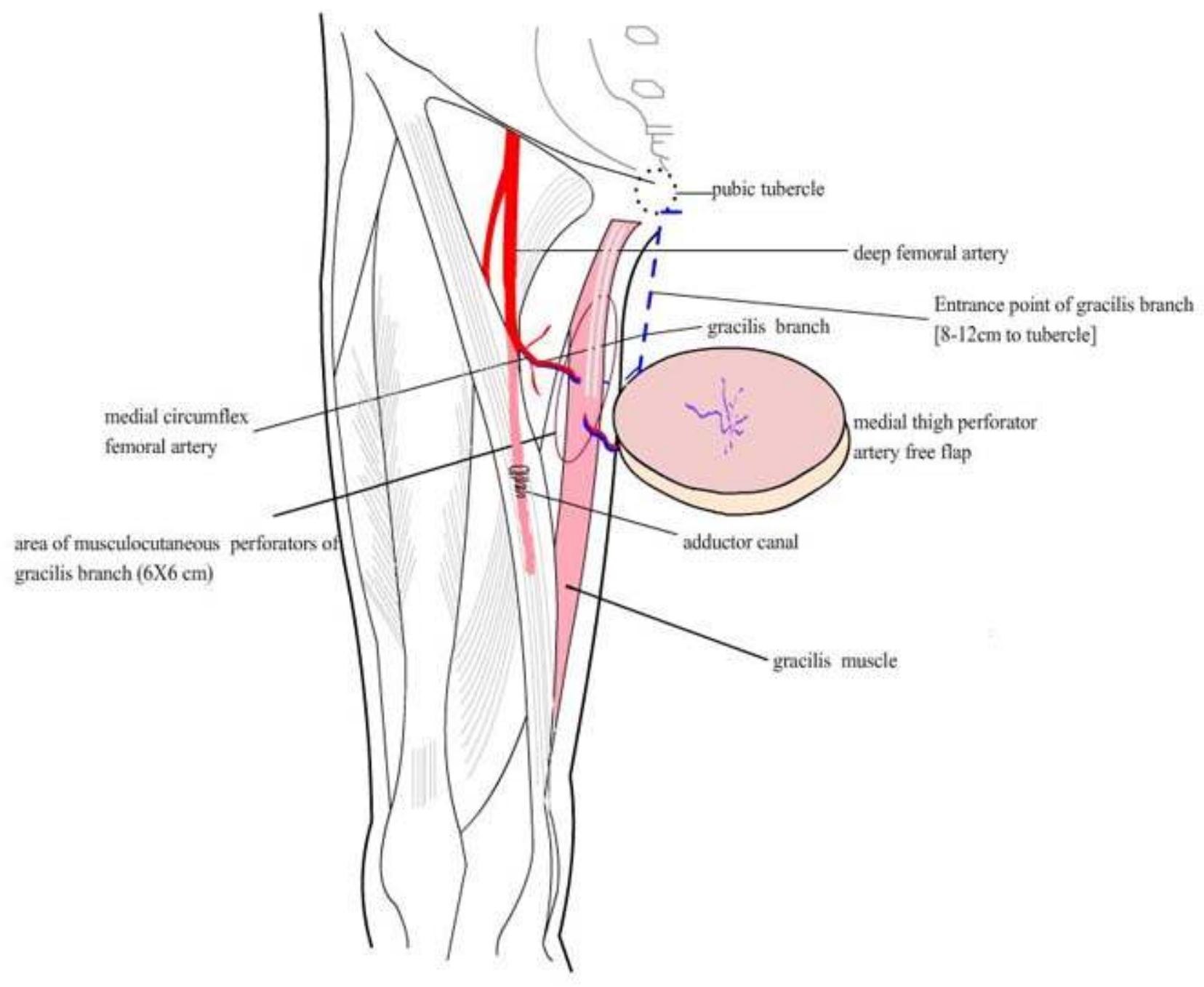

Figure 1 Schematic drawing of medial circumflex femoral artery perforator (MCFAP) flap. The gracilis musculocutaneous perforators can be found using manual doppler sonography at a point approximately $10 \mathrm{~cm}$ below the pubic tubercle in a region $6 \times 6 \mathrm{~cm}$ in diameter and just posterior to the palpable tendon of the adductor longus muscle. (Diagram drawn by Nebil Yesiloglu, MD).

Degloving injuries and high energy trauma of the distal lower extremity is fortunately rare in children and there are a limited number of papers written about microsurgical management of these injuries. ${ }^{5}$ Rinker, et al., preferred to reconstruct the defects in the distal lower extremity by harvesting the latissimus dorsi muscle flap due to a consistent vascular anatomy and a vascular pedicle of sufficient caliber, even in very small children ${ }^{6}$ whereas Van Landuyt, et al., reconstructed the degloving injuries of distal lower extremity with the deep inferior epigastric artery perforator flap with success. ${ }^{7}$ In children, donor sites for free flaps are particularly scarce because of the need for a long and reliable vascular pedicle of sufficient size. The reconstructive surgeon should consider a way to minimize donor-site morbidity from an aesthetic, functional, and psychological aspect. Perforator flaps have gained wide popularity, because of their versatility and reduced donor-site morbidity. 


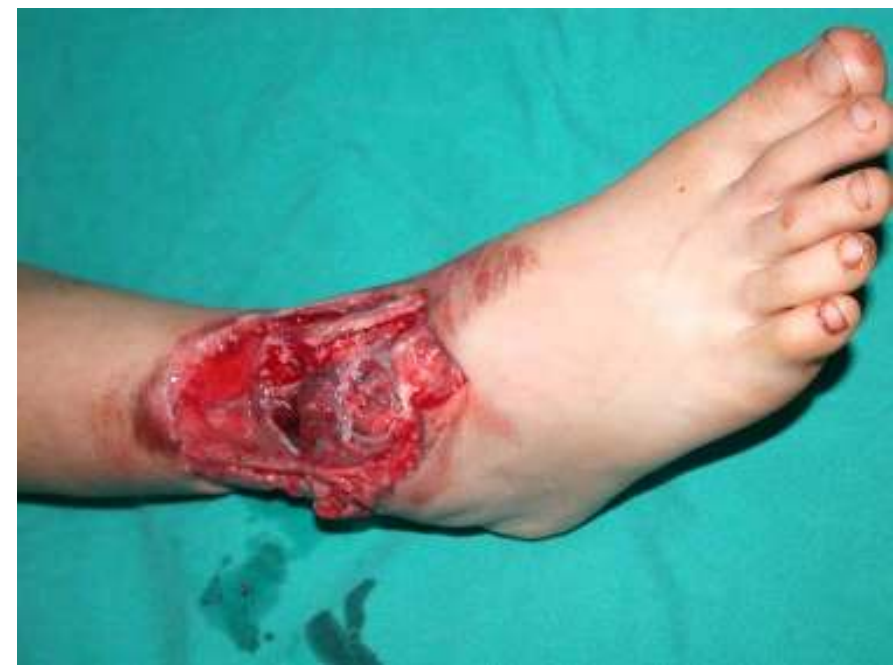

Figure 2 Pre-operative view of the injury and defect.

Their pedicles are of enough length to allow for anastomoses out of the site of injury, and the skin islands cover the same area as the traditional flaps, without any donor-site morbidity. However, the medial circumflex femoral artery perforator (MCFAP) flap has many attributes of an ideal skin flap: 1) it is a moderately large cutaneous flap, 2) the muscle need not be included, 3) the donor site defect is readily concealed by clothing, and 4) the vascular pedicle has a consistent location familiar to most reconstructive surgeons $^{8}$. There are two important issues that made the MCFAP flap ideal: 1) it has a specific skin territory that can be reliably harvested and 2) the donor site scar can be easily concealed by the gluteal fold.

The medial circumflex femoral artery generally provides the dominant pedicle to the gracilis muscle. The gracilis musculocutaneous perforators exit the muscle from an area approximately $6 \mathrm{~cm}$ wide that is centered over the hilum which is approximately 6 to $10 \mathrm{~cm}$ below the pubic tubercle. ${ }^{9,10}$ (Fig. 1) One (occasionally two) distinctly larger perforators typically exists the medial side of the muscle. Yousif, et al., performed a vector analysis as of the summation of the planar coordinates of the gracilis muscle perforators and they asserted that the true skin territory serviced by these perforators should actually have a transverse orientation parallel the medial groin crease. ${ }^{9}$
In our case report, we have confirmed the versatility and safety of the MCFAP flap in the first 24-hours after an injury in a patient who was 7-years-old and has a soft tissue defect on the anterior-lateral aspect of the ankle.

\section{Case Report}

A 7 year-old boy sustained a severe mangling, crushing type injury of his right ankle in an elevatordoor related accident. A degloving injury of the anterolateral aspect of the ankle, an ipsilateral tarsal fracture and ankle subluxation was noted. (Fig. 2) After the wound was debrided and the fracture lines reduced and fixed, the defects were then be covered immediately with a 12 x $16 \mathrm{~cm}$ free left medial circumflex femoral artery perforator flap. Informed consent was obtained from his parents.

\section{Surgical Procedure}

With the patient in a frogleg position, the required proximal gracilis muscle and its overlying skin was exposed. Using manual Doppler sonography at a point approximately $10 \mathrm{~cm}$ below, the pubic tubercle in $6 \times 6 \mathrm{~cm}$ diameter and just posterior to the palpable tendon of the adductor longus muscle, the site of any gracilis musculocutaneous perforators was marked. A template of the recipient defect is centered about this point, staying medial to the palpable femoral artery and below the groin crease. The inferoposterior margin of the flap is first incised, proceeding through the deep fascia. Blunt dissection proceeds from posterior to anterior until the more distal aspect of the gracilis muscle is found. The entire posterior portion of the flap can then be raised to the level of the muscle, which simplifies exposure of any exiting musculocutaneous perforators.

Once the origin of the perforators from the source vessels is identified, the rest of the perimeter of the flap can be safely incised. Inferiorly, branches of the greater saphenous vein are ligated. At a subfascial level below such a branch, the superficial vein can be 


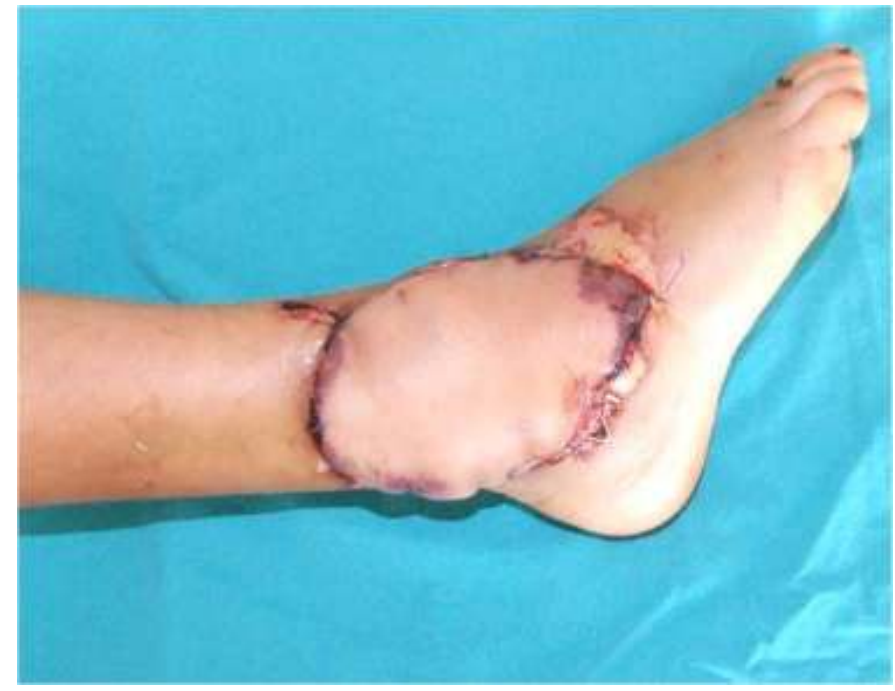

Figure 3 The great saphenous vein was also kept with the flap, and an end-to-end anastomosis performed to the great saphenous vein of the foot at the same level to provide a second source of venous outflow. There were minimal venous insufficiency on the post-operative fourth day.

followed to the anterosuperior border of the flap where it often enters the greater saphenous vein. If the medial thigh skin is redundant enough, donor site closure paralleling or within the groin crease can be accomplished primarily as in a medial thigh lift.

Only one musculocutaneous perforator was preserved with the flap. Microanastomoses were performed in end-to-end fashion to the anterior tibial artery and vein just proximal to the zone of obvious damage. The great saphenous vein was also kept with the flap, and an end-to-end anastomosis performed to the great saphenous vein of the foot at the same level to provide a second source of venous outflow. (Fig. 3) Without undermining, the donor site was closed directly resulting in an almost linear scaring of the gluteal fold that still can be easily concealed. (Fig. 4) We did not see any partial or total flap necrosis in the second year follow-up period. (Fig. 5)

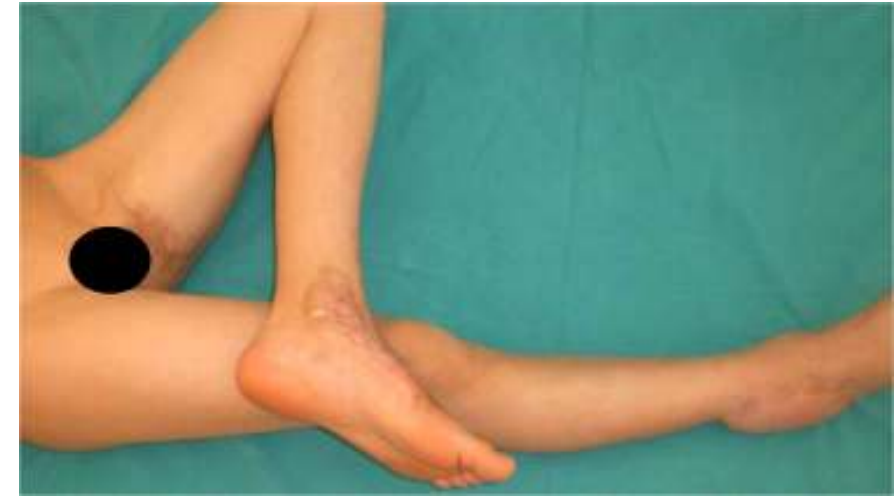

Figure 4 Post-operative view on second year. The donor site was an almost linear scar in the gluteal fold that still can be easily concealed.

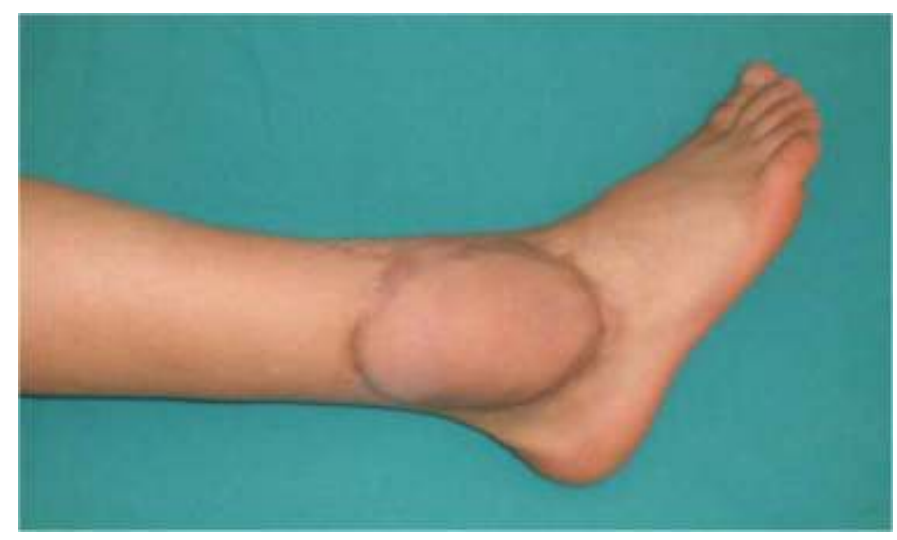

Figure 5 Partial or total flap necrosis was not seen in the second year follow-up period.

\section{Discussion}

The flap selection for lower extremity reconstruction is generally based on the location of the defect, the size of the wound surface area, the type of deficient tissue components and their volume, the status of the wound, the length of the pedicle, and the donor site and its morbidity. Muscle flaps have maintained an important role because they conform better to threedimensional wounds, obliterate dead spaces, and decrease the risk of infection ${ }^{11,12,13}$ by improving vascularity and oxygen delivery to the contaminated wound. ${ }^{14,15}$ 
These advantages of muscle or musculocutaneous flaps are responsible for their wide use in the management of extensive composite lower extremity defects. ${ }^{16,17,18,19}$ However, use of free fasciocutaneous flaps for lower extremity reconstruction has been reported much less because of their lack of bulk and inability to fill dead spaces. ${ }^{20,21}$ The distal third of the leg, especially the pretibial area, ankle, and the dorsum of foot, requires thin and pliable soft-tissue coverage of exposed bones, tendons, and joints. ${ }^{22,23,24} \mathrm{We}$ preferred to cover the anterolateral ankle defect with the medial circumflex femoral artery perforator flap that contributed thin and pliable soft tissue coverage.

In 1986, Godina reported his series of 532 patients who had received microsurgical reconstruction of the lower extremity after trauma. ${ }^{25}$ The following year Khouri and Shaw published their series of 304 cases. $^{26}$ The basic principles delineated in those large, early series are universally accepted and applied today: 1) wide debridement, and 2) early coverage with well vascularized tissue. Our patient underwent wide debriment in the first 24 hours after trauma and the defect were covered with the MCFAP. Also we did not encounter any complications such as infection, wound dishence or osteomyelities, both in the early and late periods after surgery.

Even in the pediatric population, it was realized that free flaps could be a useful tool in the treatment of soft-tissue defects, even in the early days of microsurgery. ${ }^{27,28}$ First, critical issues as to the feasibility and reliability of this type of intervention in children were rapidly overcome as it transpired that the relative size of the pedicle vessels is larger than that of adults. ${ }^{29,30}$ The same holds true for the perforator vessels; although they can be relatively small in children, their relative size compared with the size of the child's body is greater than that in adults. ${ }^{7}$ To enhance the safety and reliability of the flap, in children, as in adults, the biggest perforator should be selected; it clearly displays a pulsatile artery and at least one concomitant vein, preferentially two.
Perforator flaps provide larger flaps, longer pedicles, and less donor-site morbidity, all on well-known and sizable source vessels. Although, there is a limited number of articles reporting perforator flaps in children, in the current literature, we report that the MCFAP can be safely used to reconstruct lower extremity defects in children. We have performed the MCFAP in a 7 year-old boy and we did not observe any partial or total flap necrosis in the early and late period.

The major advantage of this flap is that the donor site scar can be easily concealed by clothing even if a skin graft is necessary to obtain closure, as opposed to any longitudinally oriented skin paddle which always leaves a vertical scar on the medial thigh. ${ }^{31}$ This is an identical advantage of the axial groin flap, which actually encompasses the lateral groin region. ${ }^{32}$ This explains the temptation to call this the "medial groin" perforator flap. Although the lateral groin flap is considered unreliable as a free flap because of the great frequency of vascular anomalies, ${ }^{32}$ on the contrary, the gracilis (medial circumflex femoral) perforator flap has dominant vascular pedicle of large caliber that is consistent in location, always has adequate musculocutaneous perforators, and is a donor site already familiar to the accomplished microsurgeon.

\section{Conclusion}

The MCFAP flap contributes thin and pliable softtissue coverage of exposed bones, tendons, and joints. The donor site scar can be easily concealed in the groin crease by clothing. We have reported that the medial circumflex femoral perforator flap could be used safely in pediatric patients in the distal one third of tibia in an acute period of trauma with success. 


\section{References}

1. Orticochea M. The musculo-cutaneous flap method. An immediate and heroic substitute for the method of delay. $\mathrm{Br} \mathrm{J}$ Plast Surg 1972 25:106-110.

2. McCraw JB, Dibbell DG, Carraway HJ. Clinical definition of independent myocutaneous vascular territories. Plast Reconstr Surg 1977 60:341-352.

3. Heckler FR. Gracilis myocutaneous, muscle flaps. Clin Plast Surg 1980 7: 27-44.

4. Hallock GG. The gracilis (medial circumflex femoral) perforator flap: a medial groin free flap? Ann Plast Surg 2003 51(6):623-626.

5. Beaty JH, Kasser JR, Rockwood CZ (Eds). Rockwood and Wilkins' Fractures in Children. 5th Edition. Philadelphia: Lippincott Williams \& Wilkins 2001 pp 983-995.

6. Rinker B, Valerio IL, Stewart DH, Pu Lee LQ, Vasconez HC. Microvascular free flap reconstruction in pediatric lower extremity trauma: A 10-year review plastic and reconstructive surgery: Plast Reconstr Surg 2005 115(6):1618-1624.

7. Van Landuyt K, Hamdi M, Blondeel P, Tonnard P, Verpaele A, Monstrey S. Free perforator flaps in children. Plast Reconstr Surg 2005 116(1):159-169.

8. Blondeel NP, Morris FZ, Hallock GG, Neligan CP. Perforator Flaps. Anatomy, Technique and Clinical Applications. 2nd Edition. Quality Medical Publishing. 2006 pp:648-649

9. Yousif NJ. The transverse gracilis musculocutaneous flap. Ann Plast Surg. 1993, 31(4):382.

10. McCraw JB, Massey FM, Shanklin KD, Horton CE. Vaginal reconstruction with gracilis myocutaneous flaps. Plast Reconstr Surg. 1976 58(2):176-183.

11. Guzman Stein G, Fix RJ, Vasconez LO. Muscle flap coverage for the lower extremity. Clin Plast Surg 1991; 18: 545552.

12. Yaremchuk MJ. Acute management of severe soft-tissue damage accompanying open fractures of the lower extremity.Clin Plast Surg 1986 13: 621-632.

13. Francel TJ, Kolk CAV, Hoopes JE, Manson PN, Yaremchuk MJ. Microvascular soft-tissue transplantation for reconstruction of acute open tibial fractures: Timing of coverage and long-term functional results. Plast Reconstr Surg 1992; 89: 478-487.

14. Mathes S J, Alpert BS, Chang N. Use of the muscle flap in chronic osteomyelitis: Experimental and clinical correlation. Plast Reconstr Surg 1982 69: 815-829.

15. Gosain A, Chang N, Mathes S, Hunt TK., Vasconez L. A study of the relationship between blood flow and bacterial inoculation in musculocutaneous and fasciocutaneous flaps. Plast Reconstr Surg 1990 86: 1152-1162.

16. Guzman Stein G, Fix RJ, Vasconez LO. Muscle flap coverage for the lower extremity. Clin Plast Surg 1999 18: 545552.

17. Heller L, Levin LS. Lower extremity microsurgical reconstruction. Plast Reconstr Surg 2001 108: 1029-1041.

18. Bostwick J, Nahai F, Wallace JG, Vasconez LO. Sixty latissimus dorsi flaps. Plast Reconstr Surg 1979; 63: 31-41.
19. Bunkis J, Walton RL, Mathes SJ. The rectus abdominis free flap for lower extremity reconstruction. Ann Plast Surg 1983 11: 373-380.

20. Yaremchuk MJ, Brumback RJ, Manson PN. Acute and definitive management of traumatic osteocutaneous defects of the lower extremity. Plast Reconstr Surg 1987 80: 1-14.

21. Khouri RK, Shaw WW. Reconstruction of the lower extremity with microvascular free flaps: A 10 year experience with 304 consecutive cases. J Trauma 1989 29: 1086-1094.

22. Chen D, Jupiter JB, Lipton HA, Shiqi L. The parascapular flap for treatment of lower extremity disorders. Plast Reconstr Surg 1989 84: 108-115.

23. Colen LB, Pessa JE, Potparic Z, Reus WF. Reconstruction of the extremity with the dorsal thoracic fascia free flap. Plast Reconstr Surg 1998 738- 744.

24. Weinzweig N, Davies BW. Foot and ankle reconstruction using the radial forearm flap: A review of 25 cases. Plast Reconstr Surg 1998 102(6): 1999-2005.

25. Godina M. Early microsurgical reconstruction of complex trauma of the extremities. Clin Plast Surg 1986 78(3): 285-293.

26. Khouri RK, Shaw WW. Reconstruction of the lower extremity with microvascular free flaps: A 10- year experience with 304 consecutive cases. J Trauma 1989 29(8): 1086-1093.

27. Harii K, Ohmori K. Free groin flaps in children. Plast. Reconstr. Surg 1975 55: 588-592.

28. Ohmori K., Harii K, Sekiguchi J, Torii S. The youngest free groin flap yet? Br J Plast Surg 1977 30: 273-276.

29. Van Beek AL, Wavak P, Zook EG. Microvascular surgery in young children. Plast. Reconstr.Surg. 1979 63: 457-462.

30. Parry SW, Toth BA, Elliott LF. Microvascular free-tissue transfer in children. Plast. Reconstr. Surg 1988 81:838-840.

31. Whetzel TP, Lechtman AN. The gracilis myofasciocutaneous flap. Vascular Anatomy Clinical Application. 1997 99:16421652.

32. Anthony JP, Mathes SJ. The groin flaps. In: Hallock GG (Ed). Fasciocutaneous Flaps. Boston, MA: Blackwell Scientific; 1992: 89-95. 